\title{
Formation of a comfortable transport infrastructure for cyclist traffic in the tourist area of Kazan
}

\author{
Aniia Ibragimova*1, and Olga Petropavlovskikh ${ }^{10000-0002-3022-8271]}$ \\ ${ }^{1}$ Kazan State University of Architecture and Engineering, 420043 Kazan, Russia
}

\begin{abstract}
This article examines the issue of cycling in Russian cities on the example of the city of Kazan. The authors come to the conclusion that the existing bicycle zones in Kazan aren't connected to each other and don't intersect complex transport hubs with high traffic intensity, therefore, cycling around the city isn't safe and comfortable. As a solution to this problem, the idea of a new combined overpass, combining a pedestrian and roadway for cyclists, is presented. In addition, it's proposed to develop the street and road network of the city of Kazan, through the construction of new bicycle paths. The combined overpass will allow for a more rational redirection of the city's traffic flows, ensure the safety of high-speed traffic and create comfortable conditions for the city's population. The construction of a bicycle path will reduce the total traffic load on the city's roads, and ensure safe movement for citizens in the central part of the city. Thus, the need to introduce and develop bicycling in our city, which entails planning not only bicycle paths, but also the construction of other transport infrastructure facilities for comfortable crossing of transport hubs with high traffic intensity by cyclists, seems obvious.
\end{abstract}

Keywords. Cycling, cycling culture, road network, combined overpass, cycle path, footpath, transport infrastructure, scheduling, cost estimate.

\section{Introduction}

Currently, the world is developing such a direction in design, which is called «Sustainable design». It takes into account the state of the environment as much as possible or environmentally sound design [1]. The issue of environmental protection is urgent. In urban space, the main source of pollution is the transport infrastructure. All over the world, there is a search for alternative eco-friendly means of transportation. The popularization of nonmotorized transport is not only free from pollutants to carry into the atmosphere, but it's also silent, useful for human health and brings economic benefits to the city [2].

The need for the construction of the overpass is due to the complex road and transport situation of a large city with a dynamically developing infrastructure and, accordingly, a significant increase in traffic flow and the level of motorization in general, which acutely affects the level of environmental pollution. In Russian cities, they are trying to introduce cycling into the urban transport system, but all events are local in nature, while it's only

${ }^{*}$ Corresponding author: anyia13@mail.ru 
possible to develop a full-fledged cycling culture in a comprehensive way. For example, in Kazan there are bicycle paths, but they are located in parks and other recreation areas, aren ' $t$ connected to each other and don't cross complex transport hubs with high traffic intensity, so cycling around the city isn't safe and comfortable.

The relevance of the work is due to the need to address the issue of unloading traffic flows in the city of Kazan, creating comfortable conditions for the city population, ensuring the safe movement of citizens in a high-traffic area, as well as protecting the environment through the construction of a new combined overpass and bicycle paths.

The following work was fulfilled by the authors:

- considering the existing and proposing new design solutions;

- making the choice of the most rational location of the object in the cramped conditions of the city;

- studying the issue of designing such structures and applying loads;

- analyzes foreign experience in designing such structures,

- calculating the main structures, making an estimate and construction scheduling;

-working out the issue of architectural expressiveness of the structure.

The novelty of the project lies in the absence of analogues of such structures on the territory of the Republic of Tatarstan and in Russia as a whole, which requires a scientific study regarding the issue of the absence of Russian regulatory documents on the design of such bridges and overpasses.

On giving the relevance of the task, the goal of the work is set: selection of the optimal solution to the problem posed using modern approaches in the field of optimal design, the creation of economical and at the same time reliable design solutions that take into account the level of stability of the structure and fit into the environment and architectural appearance.

Research object: transport infrastructure of the city of Kazan.

Subject of research: the introduction and development of cyclization in the conditions of our city, which entails the planning not only of cycling paths, but also the construction of bridges, tunnels and other structures for comfortable crossing of transport hubs with high traffic intensity by cyclists.

\section{Materials and methods}

To achieve this goal, it's planned to solve the following tasks:

- firstly, to choose a rational location of the structure and tracing the bike path, by analyzing the road network and traffic intensity in different areas of the city;

- secondly, to conduct an analysis and variant design, during which, consider two competitive options for the overpass, conduct their technical and economic comparison and choose the most suitable option for its more detailed study;

- thirdly, to carry out the design and calculation of the main structural elements of the overpass to substantiate the adopted design solutions for the main option, to carry out an estimate and construction scheduling;

- fourthly, to analyze the current state of technical regulations, normative documents, guidelines for the design of bicycle transport infrastructure, to study them and systematize the information received.

\subsection{Analysis of the current state of the city's road network}

Comprehensive solution of issues related to ensuring road safety through the use of the latest technologies and equipment is one of the prerequisites for the successful functioning of road infrastructure facilities. Based on the analysis of statistical data, most of all road accidents in 
cities occur with the participation of pedestrians, which are the largest and most vulnerable category of road users [3].

An overground crossing, despite special measures to ensure the safety of pedestrians, doesn 't guarantee complete safety of pedestrians and affects the speed limit of vehicles, the continuity of traffic, and an increase in noise levels along the highway. The presence of a large number of unregulated ground crossings also leads to a high rate of accidents and injuries. Cyclists often become participants in road accidents, since not all streets have separate paths for their movement. The overwhelming majority of these accidents are caused by the intersection of pedestrian, bicycle and transport routes [4].

One of the most effective ways to ensure the safety of pedestrians today is the construction of overhead and underground pedestrian crossings. They serve to safely cross streets, minimize the risk of road accidents and create favorable conditions for road traffic [5]. However, the underpass, considering the tightness of the conditions, a large number of descents and ascents that aren't suitable for cyclists, cannot be called the most convenient. As a result of comparing the advantages and disadvantages of the available options, in these conditions, it becomes obvious the need for competent regulation of the movement of pedestrians and cyclists by creating special bicycle paths with the use of overhead crossings. These paths should be isolated from vehicles, convenient, accessible to the population and designed to provide connection with all elements of urban infrastructure [6].

In addition, the issue of environmental protection is important. A sharp increase in the growth rates of the passenger vehicle park in the city that has taken place over the past 10-12 years has led to a significant increase in traffic flows on the city trunk network. According to official data, over the past five years, the population of the city of Kazan has grown by $5 \%$, and the number of cars in the city has increased by $25 \%$, which negatively affects the ecology of the city. Reducing car emissions around the world will have a significant positive impact on air quality, acid rain, smog, climate change [7].

\subsection{Justification of the chosen construction site}

The plan of the cycle path was developed taking into account the requirements of regulatory documents for the design of bicycle transport infrastructure, as well as the analysis of geometric parameters given in the part of the research work. When designing the route plan, the intensity of bicycle and pedestrian flows, their main concentration and directions of movement were taken into account. The main dimensions of the space for cyclists are among the main indicators currently considered in the design of urban transport infrastructure. When calculating the dimensions of structures for cycling, it's necessary to add safety clearances to the dimensions of the transport space, which must be provided in order to minimize the risk of an accident involving a cyclist [8]. In addition, a traffic management plan has been developed, which reflects a traffic management plan to ensure the safety of all road users.

Kazan is a rapidly developing city with a population of over one million, attracting a large number of tourists. In the project, the construction of an overpass is provided over a six-lane road with high traffic intensity (Kremlin Embankment), therefore, it's advisable to provide an elevated pedestrian crossing in this place so as not to interrupt the movement of motorists and not create congestion, as well as to increase the level of safety of all road users (Fig. 1). Thus, the construction of the overpass can contribute to the creation of transport conditions in Kazan, stimulating its socio-economic development.

The need to unload this section of the road is also due to the fact that the Kremlin embankment is located in the city center, near the historical center and places of mass stay of people, which creates an intersection of intensive traffic and pedestrian flows relative to other areas. The construction site is located near the bike path directly on the embankment of the Kazanka River, which will allow it to be connected to the existing bike path near Lake Kaban, 
thereby ensuring cycling through the entire central part of the city. Thus, the relevance of the task of designing and further construction of a combined overpass seems obvious.

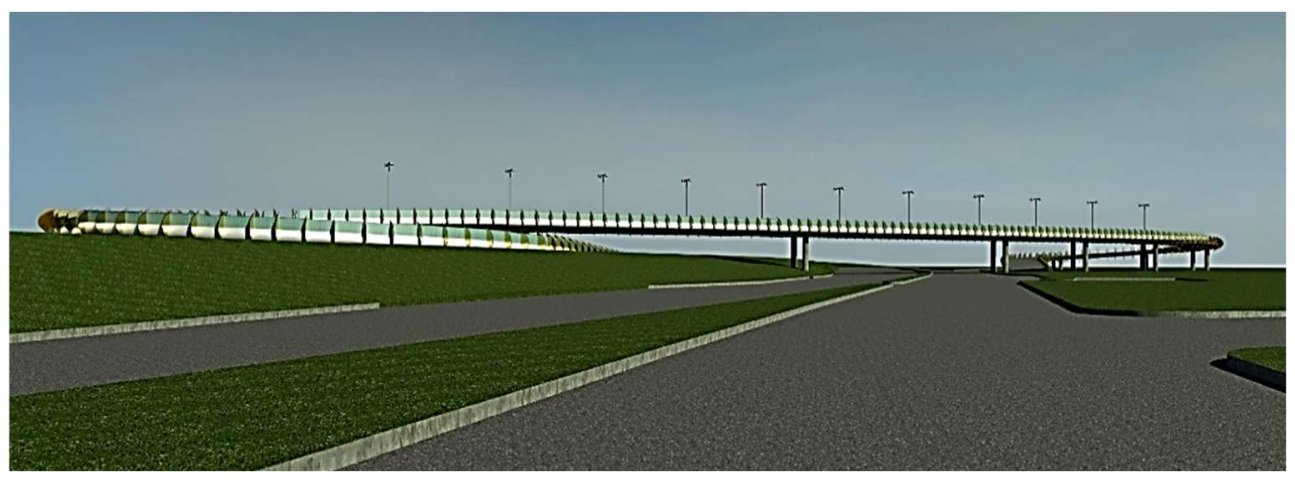

Fig. 1. Visualization of a combined overpass.

\subsection{Description of construction and used materials}

The opening of the overpass at the construction site is blocked according to the scheme $21 \times 2+24 \times 3+48 \times 3+24 \times 3 \mathrm{~m}$. The total length of the overpass along the carriageway is $354 \mathrm{~m}$. class of regulated traffic according to SP 42.13330.2016. The bridge is located on a curved plan and crosses a $40 \mathrm{~m}$ wide road at an angle of $135^{\circ}$. The elevated parts of the bridge are curved in plan with a radius of curvature of $20 \mathrm{~m}$, which is due to the longitudinal slope of the bike path, which is necessary for the comfortable movement of cyclists, as well as the cramped conditions of the city (Fig. 2).

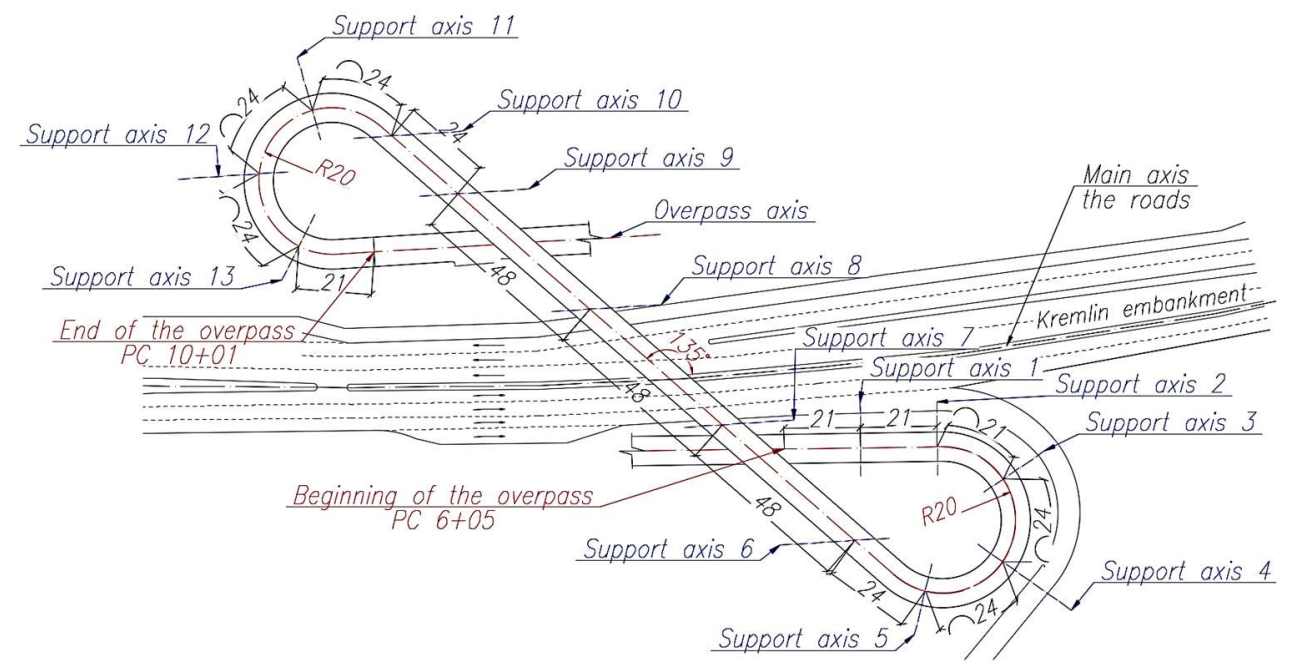

Fig. 2. Combined overpass plan.

As a result of the variant design, two variants of the overpass design were proposed; in the course of the technical and economic comparison, the most optimal was chosen. The superstructure of the combined overpass is made in the form of three parts. The road is crossed directly by a continuous superstructure made of metal I-beams according to the $48 \times 3 \mathrm{~m}$ scheme. The superstructure of the flyover sections is a reinforced concrete unstressed boxsection beam that overlaps the spans according to the schemes $21 \times 2+24 \times 3 \mathrm{~m}$ and $24 \times 3 \mathrm{~m}$. 
The overpass is designed with a width of 8 meters from the condition of placing two lanes for bicycle transport of $1.5 \mathrm{~m}$ each and a lane of the walkway of $3 \mathrm{~m}$. At the edges there are safety strips of $0.5 \mathrm{~m}$ each. In the middle there is a strip for lighting poles.

In the design part, only the metal part of the superstructure is considered. The main beams are divided in length into mounting blocks $12 \mathrm{~m}$ and $6 \mathrm{~m}$ long, joined together by a boltwelded joint - the upper chord for welding, the wall and the lower chord on high-strength bolts made of 40X «Select» steel in accordance with GOST 4543-71.

The material of the supporting metal structures is steel 10KHSND in accordance with GOST 6713-91, the type of execution is usual. For welding, steel welding wire 10NMA was used in accordance with GOST 2246-70. The load-bearing reinforced concrete structures are made of concrete of class B35 (F300 W6), reinforced with bars of the periodic profile of the grade A400 according to the Standards SP63.13330.2012 and SP35.13330.2011 [9].

The load from the weight of the superstructure is transferred to post-type supports (two posts) of circular cross-section with a diameter of $1 \mathrm{~m}$. The foundation is made of two-row bored piles with a casing pipe $0.35 \mathrm{~m}$ in diameter.

The coating of the overpass is represented by a thin-layer polymer coating for bridges based on polymethyl methacrylate, which replaces waterproofing and road clothes at transport construction sites [10]. It is used as a finishing polymer coating for pedestrian bridges and road bridges. However, it's possible to consider a more environmentally friendly surface, such as recycled tires. The drainage of the overpass water is carried out with a transverse slope of $20 \%$, the water enters the drainage trays and in the longitudinal direction is diverted outside the bridge to the treatment facilities.

\subsection{Analysis of foreign experience in the design of bicycle bridges}

The need to cross highways, complex transport junctions with high traffic intensity and other significant obstacles (rivers, railways, etc.) complicates movement, and also poses a danger to pedestrians and cyclists [11]. In such cases, it's recommended to use multi-level intersections, such as bridges and tunnels, which provide pedestrians and cyclists with the ability to safely and on the shortest path to overcome the most congested roads with heavy traffic and natural traffic barriers. Cycling is actively developing in the modern world.

Many European countries have come to the conclusion that cycling is an advantage for cities, so measures are being taken to encourage the use of bicycles as a daily means of transport [12]. However, unlike European countries that are actively developing cycling, in Russia the bicycle transport infrastructure is just beginning to be introduced within the existing road network. In this regard, in our country there are practically no regulatory frameworks and documents, as well as recommendations for the design and construction of bicycle bridges, which complicates the development of a combined overpass project. It's necessary to study the foreign experience of designing such structures in order to ensure the comfort and safety of movement of both pedestrians and cyclists and people with limited mobility (Fig. 3).

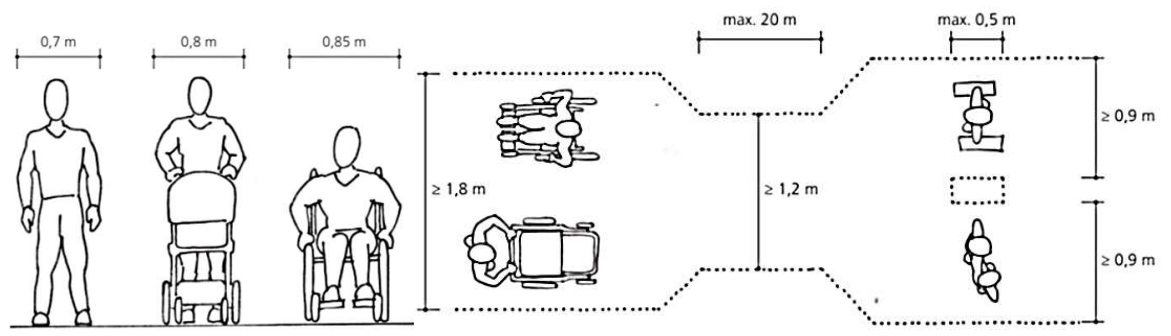

Fig. 3. Dimensions of bicycle transport infrastructure users: https://ipvdelft.com/publications/ (reference date: 04.02.2020). 
The analysis is based on several sources:

1. Album of structural elements of the arrangement [13] of the bicycle transport infrastructure - a guide to the design of the bicycle transport infrastructure in Moscow. This guideline defines the principles, guidelines and standards for the application of elements of cycling transport infrastructure and methods of its arrangement in order to support the priority of road safety and increase the share of cycling transport in Moscow.

2. PRESTO [14] - European program for the development of bicycle infrastructure and promotion of the bicycle as a full-fledged vehicle. PRESTO approaches have been tested in five cities in different European countries. The project has developed a set of concepts and practical guidelines. Most of these materials are devoted to the design of cycling infrastructure. It's noted that one of the reasons why the cyclization of Russian cities is still not developed is that there are no high-quality and modern publications on cycling infrastructure in Russian. The project has developed a set of concepts and practical guidelines.

3. Standard GOST 33150-2014 Design of pedestrian and bicycle paths - an interstate standard that is applied to the design of pedestrian and bicycle paths on public highways. This standard establishes general requirements for the design of pedestrian and cycle paths, their placement and basic parameters in order to ensure road safety and improve the transport and operational characteristics of public roads.

4. Standard SP 259.1325800.2016 Bridges in conditions of dense urban development. Design rules - this set of rules is applied to the design of new, reconstructed and overhauled permanent bridge structures, including overpasses of any type, viaducts, overpasses, pedestrian and combined bridges on highways and streets of cities with a population of 500 thousand people or more (with a coefficient building density not less than 2.0).

5. Guidelines for road design in Copenhagen «Focus on the bicycle» (translation) [15] is devoted to the design of safe bicycle roads. As Copenhagen strives to be the most cyclistfriendly city in the world, the city has clearly set policy goals to increase the proportion of Copenhagen people who choose to bike, to reduce travel times, and to improve the safety and convenience of cycling.

6. Brief Dutch Design Manual for Bicycle and Pedestrian [16] - English summary of the CROW design manual. CROW is a technology platform for transport, infrastructure and public spaces in the Netherlands. The manual was developed by one of the main Dutch bridge design organizations IPV Delft. This publication focuses on the basics of bridge design and answers to practical questions about bridge width and structure. It also lists all the factors that must be taken into account before starting a project.

In addition to the technical parameters for the design of bicycle bridge structures, the issue of the application of temporary loads from bicycle transport was studied.

The following sources were analyzed:

1. EN 1991-2: Eurocode 1: Actions on structures - Part 2: Traffic loads on bridges [17].

2. Design of bridges. Guide to basis of bridge design related to Eurocodes supplemented by practical examples.

The significance of the obtained results lies in the fact that the analysis of the sources [13-17] made it possible to effectively carry out the project of the combined overpass for construction on the basis of the developed summary table of technical standards (Table 1) and to make the right engineering decisions regarding the application of loads, as well as to determine the most unfavorable loading of the structure for further calculation. 
Table 1. Technical standards of bicycle transport infrastructure elements.

\begin{tabular}{|c|c|c|c|c|c|c|c|c|c|}
\hline \multirow[b]{2}{*}{ Technical standards } & \multicolumn{3}{|c|}{1} & 2 & \multicolumn{2}{|c|}{3} & \multirow[t]{2}{*}{4} & \multirow[t]{2}{*}{5} & \multirow[t]{2}{*}{6} \\
\hline & 声 & 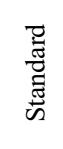 & 总总 & & 苞 & 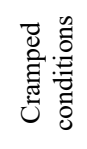 & & & \\
\hline $\begin{array}{l}\text { Overall dimensions } \\
\text { of bicycle transport } \\
\text { infrastructure users, } \\
\mathrm{m}\end{array}$ & \multicolumn{3}{|c|}{$\begin{array}{l}1 \times 2.5-\text { external links; } \\
0.75 \times 1.9-\text { a cyclist } \\
\text { Length up to } 2,0\end{array}$} & $\begin{array}{l}\text { Min aisle } \\
\text { height } 4.5 \mathrm{~m} \text {; } \\
0.9-\text { external } \\
\text { width; } \\
0.75-\text { cyclist } \\
\text { width. }\end{array}$ & $\begin{array}{c}\text { by } \\
\text { height } 2.5\end{array}$ & 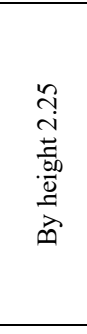 & - & - & $\begin{array}{l}0.75 \quad- \\
\text { cyclist } \\
\text { width; } \\
0.7 \quad- \\
\text { pedestrian } \\
\text { width; } \\
0.85 \quad- \\
\text { width of } \\
\text { LMP } \\
\text { groups; }\end{array}$ \\
\hline $\begin{array}{l}\text { Maximum } \\
\text { longitudinal slope, } \\
\% \text { o }\end{array}$ & 80 & 60 & 40 & 50 & 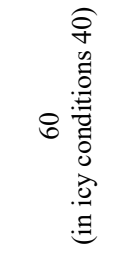 & i⿱ & $\begin{array}{l}\infty \\
0 \\
i \\
i \\
i n\end{array}$ & - & $6-10 \%$ \\
\hline $\begin{array}{l}\text { The smallest radius of } \\
\text { the curves in the plan: } \\
\text { in the absence of a } \\
\text { bend, } \\
\text { when making a } \\
\text { bend, m }\end{array}$ & 15 & 50 & 30 & - & $30-50$ & 15 & - & - & 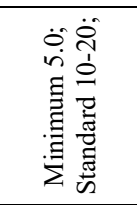 \\
\hline \begin{tabular}{|l|} 
Turn slope $(\%)$, at a \\
radius of: \\
$5-10 \mathrm{~m}$ \\
$10-20 \mathrm{~m}$ \\
$20-50 \mathrm{~m}$ \\
$50-100 \mathrm{~m}$ \\
\end{tabular} & $\begin{array}{l}- \\
30 \\
20 \\
20\end{array}$ & $\begin{array}{c}- \\
>40 \\
30 \\
20 \\
\end{array}$ & $\begin{array}{c}- \\
>40 \\
30 \\
20 \\
\end{array}$ & - & $\begin{array}{l}>30 \\
>20 \\
>15 \\
20 \\
\end{array}$ & $\begin{array}{c}30 \\
20 \\
15-20 \\
- \\
\end{array}$ & - & - & - \\
\hline $\begin{array}{l}\text { The smallest radius of } \\
\text { curves in the } \\
\text { longitudinal profile, } \\
\mathrm{m}: \\
\text { convex, concave }\end{array}$ & 400 & 500 & 600 & - & 500 & 100 & - & - & - \\
\hline $\begin{array}{l}\text { Width of a one-way } \\
\text { bike path, } m\end{array}$ & $\stackrel{n}{n}$ & $\frac{n}{n}$ & $\begin{array}{l}0 \\
\vdots \\
\vdots \\
\vdots \\
\text { ป }\end{array}$ & $\begin{array}{l}\text { Min } 0.9+0.25 \\
\text { (distance to } \\
\text { the fence); } \\
\text { Standard 2.0; } \\
\text { High quality } \\
4.0 ; \\
\end{array}$ & $1.0-1.5$ & $\frac{\vec{n}}{\stackrel{n}{0}}$ & - & $\begin{array}{l}n \\
i \\
i \\
i\end{array}$ & 1.4 \\
\hline $\begin{array}{l}\text { Width of a two-way } \\
\text { bike path (with one } \\
\text { lane in each } \\
\text { direction), m }\end{array}$ & 2.5 & 3.0 & 4.0 & Min 2.5 & $2.5-3.6$ & $\underset{i}{\stackrel{i}{~}}$ & - & 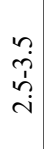 & Min 2.4 \\
\hline $\begin{array}{l}\text { The height of the } \\
\text { fence (at a distance } \\
\text { of } 0.5 \mathrm{~m} \text { from the } \\
\text { edge), } \mathrm{m}\end{array}$ & & 1.4 & & 1.2 & - & - & 1.1 & - & $1.1-1.3$ \\
\hline
\end{tabular}




\begin{tabular}{|c|c|c|c|c|c|c|c|c|c|}
\hline Bike lane width, $\mathrm{m}$ & 1.2 & 1.5 & 2 & $\begin{array}{l}\text { Min } 1.5 \text {; } \\
\text { High quality } \\
2-2.5\end{array}$ & - & - & - & ה̃ & 1.4 \\
\hline $\begin{array}{l}\text { Width of the safety } \\
\text { dividing strip of the } \\
\text { automobile and } \\
\text { bicycle road, m }\end{array}$ & \multicolumn{3}{|c|}{0.5 (or 1.0-1.5) } & Min 0.35 & - & - & - & - & - \\
\hline 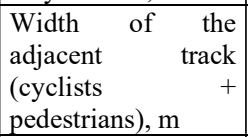 & 2.5 & 3.0 & 4.0 & $\begin{array}{l}\text { Min } 3.0 ; \\
\text { High quality } \\
4.0 \text { and more }\end{array}$ & - & - & - & - & - \\
\hline $\begin{array}{l}\text { Width of the } \\
\text { pedestrian path, } m\end{array}$ & - & - & - & - & $\begin{array}{c}0.75-4.5 ; \\
\text { Min for } \\
\text { one of the } \\
\text { two-lane } \\
0.75 ; \\
\text { single-lane } \\
\text { min } 1.0 . \\
\end{array}$ & - & 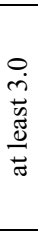 & 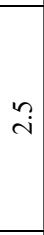 & $1.5-1.8$ \\
\hline $\begin{array}{l}\text { The width of the } \\
\text { pedestrian path, } \\
\text { taking into account } \\
\text { the low-mobility } \\
\text { groups of the } \\
\text { population, } m\end{array}$ & & - & & - & $\begin{array}{c}\text { For one- } \\
\text { sided not } \\
\text { less than } \\
1.2 ; \\
\text { for two- } \\
\text { sided not } \\
\text { less than } \\
2.0 . \\
\end{array}$ & - & - & - & - \\
\hline $\begin{array}{l}\text { Width of the verges } \\
\text { of the adjacent } \\
\text { track, } m\end{array}$ & & 0.5 & & - & 0. & & - & - & - \\
\hline $\begin{array}{l}\text { Cross slope of the } \\
\text { adjacent track, \% }\end{array}$ & & 20 & & - & $15-20$ & 20 & - & 25 & - \\
\hline $\begin{array}{l}\text { Longitudinal and } \\
\text { transverse slope for } \\
\text { people with limited } \\
\text { mobility, \%o }\end{array}$ & & - & & - & $10-40$ & - & - & - & - \\
\hline $\begin{array}{l}\begin{array}{l}\text { Distance to the side } \\
\text { obstacle, } m\end{array} \\
\end{array}$ & & $.2-0.7$ & & $0.25-0.625$ & 0. & & - & - & - \\
\hline $\begin{array}{l}\text { Minimum width of } \\
\text { the bridge, } \mathrm{m} \text { : }\end{array}$ & & - & & - & - & & 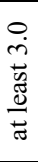 & - & $\begin{array}{l}1.5-1.8 \\
\text { pedestrian; } \\
2.4 \\
\text { bicycle. }\end{array}$ \\
\hline
\end{tabular}

\section{Results}

\subsection{Scheduling of construction}

The work schedule is executed in the project management program «Spider Project». It establishes the sequence and duration of the main types of work that ensure the construction of a bridge structure in a timely manner with the lowest labor costs and the most expedient use of machines and mechanisms [18]. To draw up a calendar schedule, the structural diagram of the bridge, the technology of erecting supports and spans were studied and analyzed, and the production capacity of the bridge-building organization was estimated. As a result of the work, a production schedule was created with performance leveling, reports on materials and resources were drawn up. The duration of construction, according to the created work schedule, will be 224 days ( 7 months). 


\subsection{Estimated calculation of the construction of a combined overpass}

Estimated calculation is made in the software package Grand-SMETA 8.1. The main purpose of the GRAND-SMETA software package is to compile all types of estimate documentation to determine the cost of construction.

In this case, the calculation was made by the basic-index method based on the list of the main volumes of work. The base-index method for determining the estimated cost makes it possible to obtain the most relevant cost indicators in relation to the date of the estimate. The base-index method for determining the cost of construction is based on the use of a system of current and forecast indices in relation to the cost determined at the base price level (as of 01.01.2000) [19]. In this case, the Federal Collection of Unit Rates (FER) and the Federal Collections of Estimated Prices for Materials, Products and Structures (FSSTsm-2001) were used. Indices can be used to convert the base value to current (forecast) prices. According to the calculation results, the cost of 1 running meter is $281,545,145$ thousand rubles. The results of the estimated calculation by section are shown in Table 2 .

Table 2. Estimated results.

\begin{tabular}{|l|c|}
\hline \multicolumn{1}{|c|}{ Estimated results: } & Total value, rub \\
\hline Total for section 1 Construction of intermediate bridge bearings 1-13 & 2245619 \\
\hline $\begin{array}{l}\text { Total for section 2 Construction of the intermediate bridge bearings 2-12 and } \\
\text { transom }\end{array}$ & 1054432 \\
\hline Total for section 3 Construction of the abutment wall & 462833 \\
\hline Total for section 4 Construction of embankments approaches & 124402 \\
\hline Total for section 5 Mounting of superstructures & 3640852 \\
\hline Total for section 6 Bridge coating device & 1132367 \\
\hline Total & 8660505 \\
\hline Including: & 7392974 \\
\hline Materials & 628255 \\
\hline Machines and mechanisms & 238353 \\
\hline Payroll Fund & 271495 \\
\hline Overhead & 189294 \\
\hline Estimated profit & 77424914.7 \\
\hline $\begin{array}{l}\text { Conversion index/Resolution of the Cabinet of Ministers of the Republic of } \\
\text { Tatarstan №1169 dated 12/19/2019, clause 7.3/k=8.94 }\end{array}$ & 77424915 \\
\hline Total subject to add. work and costs & 15484983 \\
\hline VAT 20\% (Value added tax) & 92909898 \\
\hline TOTAL by estimate & \\
\hline
\end{tabular}

\subsection{Technical standards for cycling infrastructure facilities}

The authors carried out a search for alternative foreign standards, combined with an analysis of the existing regulatory and technical documents for the design and construction of bicycle and pedestrian bridges and detached paths. As a result of the study and analysis of sources, a summary table of technical standards for the design of cycling transport infrastructure is provided. 


\subsection{Calculation of the most unfavorable load}

In this work, 4 types of loading are accepted, based on the analysis of foreign design codes and rules.

1. Car wheel load - occupies the extreme left position, at a distance of $0.55 \mathrm{~m}$ from the barrier, excluding the crowd.

2. Crowd - occupies the entire width of the bridge.

3. Cyclists - occupy the left half of the overpass intended for cycling traffic.

4.Cyclists + crowd - cyclists occupy the left half of the overpass intended for the movement of bicycle traffic, and the pedestrian load occupies the right part of the overpass, which is the passable part.

The ordinates of the line of influence of actions on the main beams are determined graphically.

Live load from special equipment with an axle force $P_{A K}=10 \cdot 6 / 2=30 \mathrm{kN}$ with loading length $\lambda=48 \mathrm{~m}$ installed as two concentrated loads in the most unfavorable place - in the middle of the span [20]. The width of the wheelbase is taken as $2.45 \mathrm{~m}$. The dynamic coefficient for this type of transport is taken equal to 1.0, taking into account the speed of its movement, equal to $30 \mathrm{~km} / \mathrm{h}$.

The temporary equivalent uniformly distributed linear load from the crowd over the entire width of the bridge with a load length $\lambda=48 \mathrm{~m}$ will be:

$$
P_{T}=k_{T} \cdot P \cdot \mathrm{b}=1 \cdot 4 \cdot 8=32 \mathrm{kN} / \mathrm{m}
$$

where $P=4 \mathrm{kN} / \mathrm{m}^{2}$ - the intensity of the load from the crowd of pedestrians; $b$ - loading width.

The temporary equivalent uniformly distributed linear load from bicycle transport over half the width of the bridge with a load length $\lambda=48 \mathrm{~m}$ will be:

$$
P_{T}=k T \cdot P \cdot b=0.875 \cdot 3.4 \cdot 4=12.25 \mathrm{kN} / \mathrm{m} \text {, }
$$

where $P=2.0+120 /(48+30)=3.5 \mathrm{kN} / \mathrm{m}^{2}$ - the intensity of the load from bicycle transport; $b$ - loading width.

The temporary equivalent uniformly distributed linear load from bicycle transport over half the width of the bridge and the load from a crowd of pedestrians on the other half of the bridge with a load length $\lambda=48 \mathrm{~m}$ will be:

$$
P_{T B}=k_{T 1} \cdot P_{1} \cdot b_{1}+k_{T 2} \cdot P_{2} \cdot b_{2}=0.875 \cdot 3.5 \cdot 4+0.125 \cdot 4 \cdot 4=14.25 \mathrm{kN} / \mathrm{m}
$$

where $\mathrm{P}_{1}=2,0+120 /(48+30)=3,5 \mathrm{kN} / \mathrm{m}^{2}$ - the intensity of the load from bicycle transport; $\mathrm{P}_{2}=4 \mathrm{kN} / \mathrm{m}^{2}-$ the intensity of the load from the crowd of pedestrians;

$\mathrm{b}_{1}$ - the width of the bicycle load;

$b_{2}-$ the width of the load from the crowd of pedestrians.

Table 3. Estimated time equivalent evenly distributed load.

\begin{tabular}{|l|c|}
\hline \multicolumn{1}{|c|}{ Load } & $\begin{array}{c}\text { Calculated value, } \\
\mathrm{kN} / \mathrm{m} \\
\mathrm{t} / \mathrm{m}\end{array}$ \\
\hline \multirow{2}{*}{ The load from the crowd of pedestrians } & 32 \\
& 3.26 \\
\hline \multirow{2}{*}{ Load from bicycle transport } & 12.25 \\
& 1.25 \\
\hline \multirow{2}{*}{ The load from bicycle transport and from the crowd of pedestrians } & 14.25 \\
& 1.45 \\
\hline
\end{tabular}




\section{Discussion}

\subsection{The issue of the absence of domestic regulatory documents on the design of bicycle and pedestrian artificial structures}

The relevance of the study lies in the search for the necessary solutions for the design of bicycle bridges, combined bicycle and pedestrian overpasses and other objects of bicycle infrastructure on the territory of the Russian Federation.

The significance of the results obtained lies in the fact that the analysis of the sources made it possible to efficiently complete the project of the combined overpass and make the right engineering decisions for construction based on the developed summary table of technical standards.

\subsection{The issue of loads application}

The structures of the superstructure are designed for the temporary load from special maintenance equipment ( 6 tons), and the load from bicycle transport and the crowd is also taken into account. In addition to the technical parameters for designing bicycle bridge structures, the question of applying temporary loads from bicycle transport was studied. The following sources were analyzed:

1. EN 1991-2: Eurocode 1: Actions on structures - Part 2: Traffic loads on bridges.

2. Design of bridges. Guide to basis of bridge design related to Eurocodes supplemented by practical examples.

As a result of studying the question posed, some conclusions were drawn. To calculate the bridge structure with pedestrian and bicycle traffic along it, it's proposed to distinguish three groups of loads: the load from random transport, the load from the crowd, and the load from bicycle riders. As a random transport, the load from snow-cleaning machines is assumed, but if special measures are taken to prevent the transport from getting onto the pedestrian bridge, it's allowed not to take into account the transport load. As a load from cycling, it's recommended to apply a load equal to $5 \mathrm{kH} / \mathrm{m}^{2}$, but in cases where this loading model isn't applicable, it's allowed to calculate the load from cycling according to the following formula:

$$
q=2.0+(120 / L+30) \mathrm{\kappa H} / \mathrm{M}^{2} \text {. }
$$

In this paper, we will accept 4 types of loading, based on the analysis of foreign standards and design rules.

1. Car wheel load - occupies the extreme left position, at a distance of $0.55 \mathrm{~m}$ from the barrier fence, excluding the crowd.

2. Crowd-occupies the entire width of the bridge.

3. Cyclists - occupy the left half of the overpass, designed for the movement of bicycle transport.

4. Cyclists + crowd - cyclists occupy the left half of the viaduct, designed for the movement of bicycle transport, and pedestrian loading occupies the right side of the viaduct, which is a passer-by.

Based on the results of the calculation, it can be concluded that the most unfavorable load from bicycle transport and from the crowd of pedestrians, which is $14.25 \mathrm{kN} / \mathrm{m}$. The most unfavorable loading is taken into account in further structural analysis.

\subsection{Architectural expressiveness}

The chosen construction site dictates its own conditions for the architectural expressiveness of the structure. Since the bridge is located in the center of the city, increased requirements are imposed on its external appearance, it`s necessary it to fit into the environment (Fig. 4). 
As a result, the option of a completely closed passage was rejected, and any canopy was also excluded so as not to load an already high structure. In addition, the bridge offers a good view of the sights of the city, so glazing of the bridge doesn 't make sense. The Kremlin embankment is located in the city center, near the historic center and places of mass recreation of people, which creates an intersection of intense traffic and pedestrian flows relative to other areas. In this particular case, a special decorative retaining railing has been chosen, which combines a traditional ornament with an appropriate color scheme (Fig. 5). The structure of the fence is facilitated by perforations and the presence of a transparent glass panel. In addition, at night the bridge can be decorated with diode illumination built into the glass part of the fence.

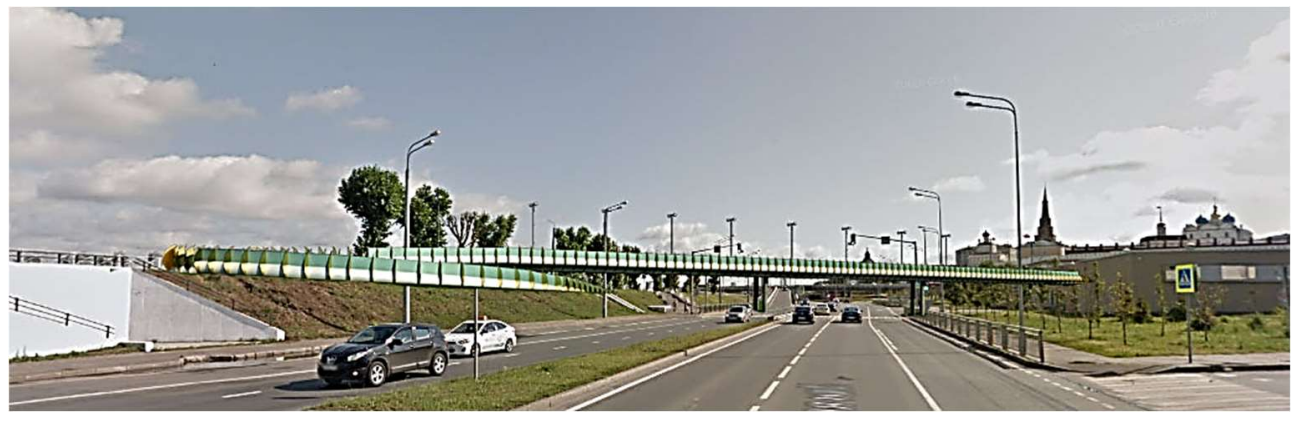

Fig. 4. The location of the overpass.

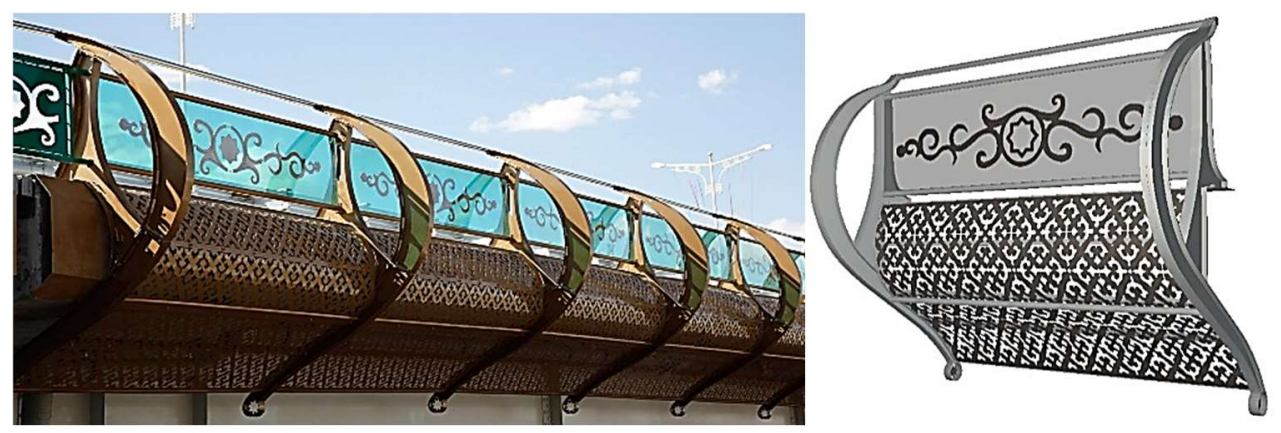

Fig. 5. Decorative retaining fence (https://dorsnab.pro/products/dekor-ogr/doms-mm4/).

\section{Conclusion}

This project is aimed at solving the issues of introducing bicycle transport into the infrastructure of Kazan, as well as the issues of developing a project for a combined overpass through the Kremlin Embankment. Tasks were set and solved that allowed us to achieve the main goal of the work by analyzing the street and road network of the city, studying the conditions of the construction area, variant design, construction and calculation of the main structural elements of the overpass to justify the design solutions made for the main version of the overpass design.

To solve the above tasks, licensed software is used, such as: the software calculation complex «LiraSAPR», the software complex for drawing up and checking estimated calculations «Grand-SMETA», the project management program «Spider Project», etc.

The project provides for the main requirements of Standard SP.35.13330.2011, including ensuring the reliability, durability and uninterrupted operation of the structure, as well as the safety and smoothness of the movement of vehicles, safety for pedestrians, labor protection during construction and operation, and environmental protection during construction. 
The implementation of this project can contribute to the creation of transport conditions in Kazan that stimulate its socio-economic development. Thus, the presented work clearly belongs to the list of priority areas of the urban economy of the city of Kazan, has practical significance primarily for the residents of the city, as well as for the design, construction and maintenance enterprises of the republic.

\section{References}

1. I.G. Ovchinnikov, I.I. Ovchinnikov, A.B. Karakhanyan. Pedestrian bridges of modernity: design trends. Part 1. Using the bionic approach, Online journal of Science Studies 72 (27), 110 (2015).

2. A.A. Evseeva, A.I. Ignatiev. Analysis of the use of the experience of countries with developed cycling infrastructure in order to improve traffic safety in G. Saratov, Scientific Thought 2, 123-129 (2015).

3. E.A. Vdovin, V.F. Stroganov, N.V. Konovalov. Modification of Road Soil Cement with Activated Fillers, Lecture Notes in Civil Engineering 150, 335-345 (2021).

4. K. Chebanyuk, O. Prasolenko, D. Burko [et al.]. Pedestrians influence on the traffic flow parameters and road safety indicators at the pedestrian crossing, Transportation Research Procedia, Rome, 858-865 (2020).

5. H. Rutter. Health economic assessment tool for cycling (HEAT for cycling), Copenhagen: WHO Regional Office for Europe, 46 (2011).

6. P.N. Yumashev, A.M. Tingaev. Bicycles as a part of the urban environment, Alley of Science 1 (28), 247-253 (2019).

7. S.M. Maksimova, A.V. Melnikova, S.Yu. Kazantseva, S.V. Danilov. Evaluation of the effect of the development of cycling infrastructure in a megapolis, Economy: yesterday, today, tomorrow 9 2-1, 18-32 (2019).

8. O.A. Loginova, R.R. Khairutdinova. Design of bicycle paths, Transport equipment and technology 2 (17), 18 (2020).

9. E.A. Vdovin, V.F. Stroganov. Optimization of complex frost-resisting additives in line with operational requirements towards freezing temperature in road dressing constructions, IOP Conference Series: Materials Science and Engineering 832 1, (2020).

10. R. Galeev, R. Nizamov, L. Abdrakhmanova, V. Khozin. Resource-saving polymer compositions for construction purposes, IOP Conference Series: Materials Science and Engineering 890 1, (2020).

11. A.V. Tsokur, E.V. Denisenko. Principles of phased introduction of bicycle infrastructure in the urban environment, Izvestija KSUAE 4 (42), 117-128 (2017).

12. M.L. Hoffmann. Bike lanes are white lanes: Bicycle advocacy and urban planning, 1-196 (2016).

13. Album of structural elements for the arrangement of bicycle transport infrastructure, StroyInvest. URL: https://transport.mos.ru/common/upload/public/file/albom_velo.pdf (reference date: 04.02.2020).

14. D. Dufour. PRESTO Cycling Policy Guide: Promoting Cycling for Everyone as a Daily Transport Mode, Netherlands, (2010).

15. Bicycling of St. Petersburg, Recommendations for road design in Copenhagen «Bicycle in focus». URL: https://velosipedization.ru/focus-on-cycling/docs/CykelFokus_RU.pdf (reference date: 04.02.2020).

16. Brief Dutch Design Manual for Bicycle and Pedestrian (Brief Dutch guide to designing bicycle and pedestrian bridges) URL: https://ipvdelft.com/publications/ (reference date: 04.02.2020).

17. EN 1991-2: Eurocode 1: Actions on structures - Part 2: Traffic loads on bridges. 
18. O.K. Petropavlovskikh, O.A. Loginova, D.R. Apakova [et al.]. Project management in the construction of artificial structures, Izvestija KSUAE 2 (48), 290-299 (2019).

19. A.S. Ovsyannikov, V.A. Bolgov. Adaptation of variants of the base-index method for determining the cost of construction for modern conditions, Problems of modern economic, legal and natural sciences in Russia: collection of articles ii of the international scientific-practice conference, 72-74 (2014).

20. I.Yu. Maystrenko, T.A. Zinnurov, D.I. Erohin, T.I Maystrenko. Analysis of the efficiency of obtaining reliable data when operating with number sets in simulation of bridges structural components, IOP conference series: Materials Science and Engineering 890, 012030 (2020). DOI: 10.1088/1757-899X/890/1/012030. 